\title{
Ethephonin vaikutus marjojen irtoamiseen ja kypsymiseen eräissä Suomessa viljellyissä herukkalajikkeissa
}

\author{
Erkki Kaukovirta ja Outi Murto \\ Yliopiston puutarhatieteen laitos, Viikki
}

\section{Effects of ethephon on fruit ripening and abscission in some black and red currant varieties cultivated in Finland}

\author{
ErkKi Kaukovirta and Outi Murto \\ University of Helsinki, Departement of Horticulture, 00710 Helsinki
}

\begin{abstract}
Sprays of (2-Chloroethyl) phosphonic acid (ethephon) were applied as a means of easing the process of harvesting and reducing the proportion of green fruit to 'Brödtorp', 'Wellington XXX' and 'Risager' black currants and 'Rondom' red currents in 3 different experiments and at various locations. Fruits were harvested by hand shaking (5 sec.) 4 days after treatment.

Ethephon promoted loosening of the fruits from all cultivars. Premature fruit drop increased with increasing ethephon concentration and was $0.6-13.1 \%$ at $250 \mathrm{ppm}$, $16.7-78.9 \%$ at $500 \mathrm{ppm}$ and $34.1-84.0 \%$ at $1000 \mathrm{ppm}$ depending on cultivar and experimental conditions. The proportion of pre-harvest fruit shedding induced by ethephon at $500 \mathrm{ppm}$ or more was greatest from two year old 'Brödtorp' black currant bushes.

The proportion of green fruit in two year old 'Brödtorp' bushes was reduced, but not in older bushes or in other cultivars. Over ripening of mature red currants fruits was promoted by all concentrations, but this response in black currants varied according to concentration and cultivar. The influence of ethephon treatments on sugar and vitamin $\mathrm{C}$ contents was not consistent; both increases and decreases were observed.

The cultivars 'Risager' and 'Brödtorp' were more sensitive to leaf abscission induced by ethephon treatments than were 'Wellington' or 'Rondom'. Application at $250 \mathrm{ppm}$ to 'Risager' led to increased leaf abscission within 4 days and to 'Brödtorp' within in 2 weeks. Also for other cultivars higher concentrations were needed to induce leaf abscission.
\end{abstract}

Ethephonia (2-kloorietyylifosforihappo), joka kasvisolussa hajaantuessaan synnyttää etyleeniä, käytetään mm. edistämään hedelmien ja eräiden puutarhamarjojen kypsymistä ja irtoamista (de WILDE 1970). Sen on todettu vähentävän mm. mustaherukan marjojen irrottamiseen tarvittavaa voimaa sekä edistävän marjojen tasaista kypsymistä (LUCKwILl 1968, INGRAM 1969, TRUSHECKIN ym. 172), joskin teho eri koeolosuhteissa on ollut erilainen (INGRAM 
1972). Tehovaihtelua aiheuttavia tekijöitä ei herukalla ole selvitetty, mutta etyleenin vapautumisen ethephonista tiedetään olevan lämpötilasta riippuvaisen (LougheEd ja FrankLin 1972). Lisäksi muilla kasveilla tehtyjen tutkimusten perusteella voidaan eri lajikkeiden alttiudessa ethephonkäsittelylle otaksua olevan selviä eroja (Fiorino ym. 1970, CANTLIFfe ja Goodwin 1975).

Nyt selostettavassa tutkimuksessa selvitettiin poimintaa edeltävän ethephon-käsittelyn vaikutusta eräisiin Suomessa viljeltäviin herukkalajikkeisiin.

\section{Aineisto ja menetelmät}

Kokeet 2-kloorietyylifosforihapon vaikutuksesta herukan marjojen irtoamiseen tehtiin v. 1970 kolmessa koepaikassa: puutarhatieteen laitoksessa Viikissä, Paimion maatalouskerho-opistossa ja K. Kotitalon tilalla Tarvasjoella. Pensaat olivat Viikissä 2., Paimiossa 3. ja Tarvasjoella 9. satokauttaan kasvavia. Lajikkeet ilmenevät tulostaulukoista. Paimiossa herukkapensaat olivat aitaviljelyssä, muissa paikoissa vapaasti kasvavia. Kerranteita oli Viikissä 3, muissa koepaikoissa 4. Kokeiden aikaiset lämpöolot ja sädemäärät on esitetty taulukossa 1 .

Kokeissa käytetty ethephon (2-kloorietyylifosforihappo) oli Amchem 68-250- valmistetta (Ethrel). Ruiskuteliuosten pitoisuudet ilmenevät tulostaulukoista. Ruiskutukset tehtiin viikkoa ennen kuin marjojen arvioitiin saavuttavan korjuukypsyyden ja tällöin ruiskuteliuosta käytettiin niin paljon, että pensaat kastuivat täysin. Käsittelyn yhteydessä suojattiin pensaiden alustat muovilla ennen sadonkorjuuta varisseiden marjojen poiminnan helpottamiseksi. Sato korjattiin 4 vrk:n kuluttua käsittelystä. Tämän lisäksi Viikin kokeessa oli koejäsenet, joissa korjuupäivä oli 6 ja 8 vuorokauden kuluttua käsittelystä.

Kokeissa mitattiin ennen korjuuta irronneet, poiminnassa irronneet ja pensaaseen jääneet marjat sekä punnittiin irronneet lehdet. Marjojen kypsyysaste määritettiin $\mathbf{1 0 0 - 5 0 0}$ g:n satunnaisnäytteistä korjuupäivänä ja 1, 2, 3 ja 4 päivää korjuun jälkeen. Lisäksi Viikin kokeessa määritettiin marjojen kuivapaino ja Paimion ja Tarvasjoen kokeesta määritettiin Huhtamäki Oy:n laboratoriossa askorbiinihappopitoisuus potentiometrisesti Kontron ja CASAgranden (1945) mukaan ja inverttisokeri Bertrandin titrimetrisellä menetelmällä (ACKER 1967).

\section{Tulokset ja tulosten tarkastelu}

Vaikutus marjojen irtoamiseen

Ethephon lisäsi vesiruiskutukseen verrattuna selvästi marjojen irtoamista poimintaravistelussa kaikilla koepaikoilla ja kaikista koelajikkeista (kuva 1, taulukko 2). Ennen poimintaa irronneiden marjojen osuus oli mustaherukalla sitä suurempi mitä suurempi vaikuttavan aineen pitoisuus oli ( $\left.\mathrm{F}=206.54^{* * *}\right)$.

Lajikkeiden reaktioherkkyydessä ethephon-käsittelyyn nähden oli eroja, jotka ilmenivät ennen muuta ennen poimintaa varisseiden marjojen määrissä (kuva 1). Kaikki ruiskutepitoisuudet huomioon ottaen jäi mustaherukkalajik- 
Taulukko 1. Lämpöolot ja sademäärä koepaikkakunnilla havaintojaksoittain.

Table 1. Temperature conditions and the amount of precipitation at experimental locations.

\begin{tabular}{|c|c|c|c|}
\hline $\begin{array}{l}\text { Jakso } \\
\text { Period }\end{array}$ & $\begin{array}{c}\text { Keskilämpö- } \\
\text { tila } \\
\text { Average } \\
\text { temperature } \\
{ }^{\circ} \mathrm{C}\end{array}$ & $\begin{array}{c}\text { Lämpö- } \\
\text { summa } \\
\text { Heat } \\
\text { summation }\end{array}$ & $\begin{array}{c}\text { Sademäärä } \\
\text { Precipitation } \\
\text { mm }\end{array}$ \\
\hline $\begin{array}{r}\text { Tervasjoki - MUSTaherukKa } \\
\text { BLAcKcurRant }\end{array}$ & & & \\
\hline $\begin{array}{l}\text { Käsittely - korjuu } \ldots \ldots \ldots \ldots \ldots \ldots \ldots \ldots \ldots \ldots \ldots \\
\text { Treatment }- \text { harvest }\end{array}$ & 16.9 & 59.7 & 15.4 \\
\hline $\begin{array}{l}\text { Korjuu }-1 \text { vk käsittelystä ............ 4. 4. }-8.8 . \\
\text { Harvest }-1 \text { week after treatment }\end{array}$ & 14.8 & 48.9 & 4.9 \\
\hline $\begin{array}{l}1-2 \text { vk käsittelystä ....................... 9. } 9 .-13.8 . \\
1-2 \text { weeks } a . \text { treatm. }\end{array}$ & 15.3 & 51.4 & 7.0 \\
\hline $\begin{array}{r}\text { Paimio - MUSTAHerukat } \\
\text { BLACKCURRAMTS }\end{array}$ & & & \\
\hline $\begin{array}{l}\text { Käsittely }- \text { korjuu } \ldots \ldots \ldots \ldots \ldots \ldots \ldots \ldots \ldots \ldots \ldots \ldots \ldots \ldots \ldots \\
\text { Treatment }- \text { harvest }\end{array}$ & 16.3 & 56.4 & 6.0 \\
\hline 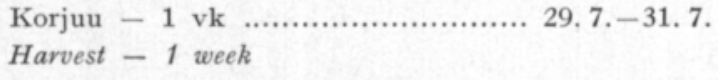 & 15.1 & 44.3 & 16.7 \\
\hline $\begin{array}{l}1-2 \text { vk ....................................... } 1.8 .-7.8 . \\
1-2 \text { weeks }\end{array}$ & 16.5 & 80.3 & 0.1 \\
\hline $\begin{array}{r}\text { Paimio - PUNaherukKa } \\
\text { REDcurRant }\end{array}$ & & & \\
\hline $\begin{array}{l}\text { Käsittely - korjuu } \ldots \ldots \ldots \ldots \ldots \ldots \ldots \ldots \ldots \ldots \ldots \ldots \ldots \\
\text { Treatment }- \text { harvest }\end{array}$ & 17.2 & 61.1 & 0.1 \\
\hline 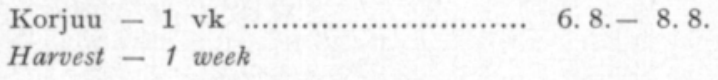 & 13.8 & 26.4 & 4.9 \\
\hline 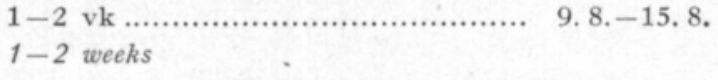 & 15.4 & 72.9 & 11.9 \\
\hline $\begin{array}{r}\text { VIKKI - MUSTAHERUKKA } \\
\text { BLACKCURRANT }\end{array}$ & & & \\
\hline $\begin{array}{l}\text { Käsittely }+4 \text { vrk } \ldots \ldots \ldots \ldots \ldots \ldots \ldots \ldots \ldots \ldots \ldots \ldots \ldots \ldots \ldots \\
\text { Treatment }+4 \text { days }\end{array}$ & 16.7 & 58.4 & 9.8 \\
\hline $\begin{array}{l}\text { Käsittely }+6 \text { vrk } \ldots \ldots \ldots \ldots \ldots \ldots \ldots \ldots \ldots \ldots \ldots \ldots \ldots \ldots \ldots \\
\text { Treatment }+6 \text { days }\end{array}$ & 16.7 & 81.8 & 15.8 \\
\hline $\begin{array}{l}\text { Käsittely }+8 \text { vrk } \ldots \ldots \ldots \ldots \ldots \ldots \ldots \ldots \ldots \ldots \ldots \ldots \ldots \ldots \\
\text { Treatment }+8 \text { days }\end{array}$ & 17.0 & 107.8 & 17.9 \\
\hline
\end{tabular}




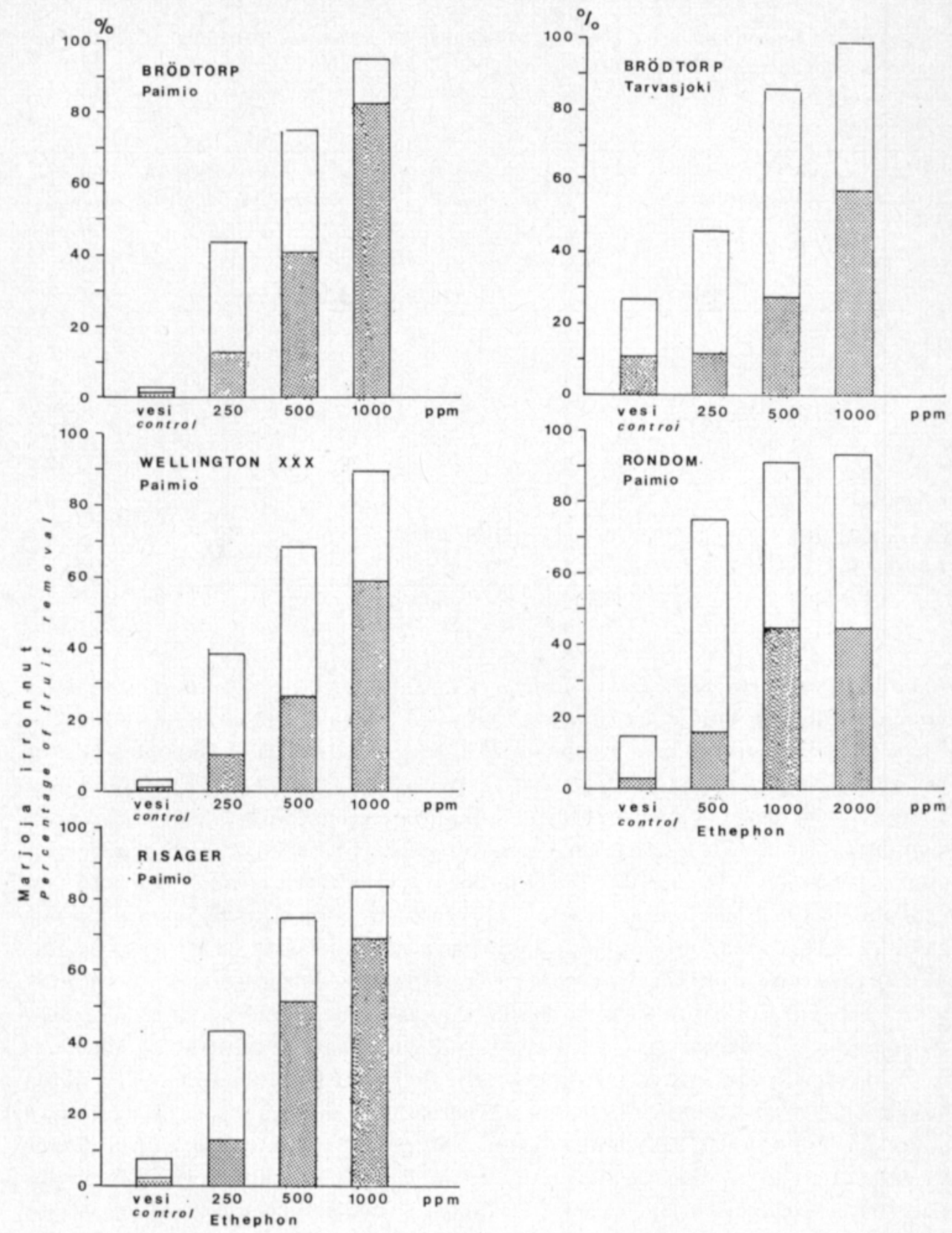

Kuva 1. Ethephonin vaikutus musta- ja punaherukan marjojen irtoamiseen ennen korjuuta (pylvään alaosa) ja ravitettaessa (pylvään yläosa).

Fig. 1. Effects of ethephon on fruit removal of black and red currants before harvest (the lower part of diagrams) and at harvest (the upper part of diagrams).

keella 'Wellington $\mathrm{XXX}\left(\mathrm{F}=8.97^{* * *}\right)$ ja 'Rondom'- punaherukalla varisseiden marjojen määrä pienemmäksi kuin muilla lajikkeilla, mutta oli kyseisilläkin lajikkeilla selvästi suurempi kuin kirjallisuudessa esitettyjen tietojen valossa voitiin odottaa (LUCKWILL 1968). Ennen poimintaa irronneiden marjojen 
Taulukko 2. Ethephonin (500 ppm) ja korjuupäivän vaikutus 'Brödtorp' mustaherukan marjojen irtoamiseen. Viikki 1970.

Table 2. Effects of ethephon (500 ppm) and date of harvest on fruit removal of 'Brödtorp' blackcurrant. Viikki 1970.

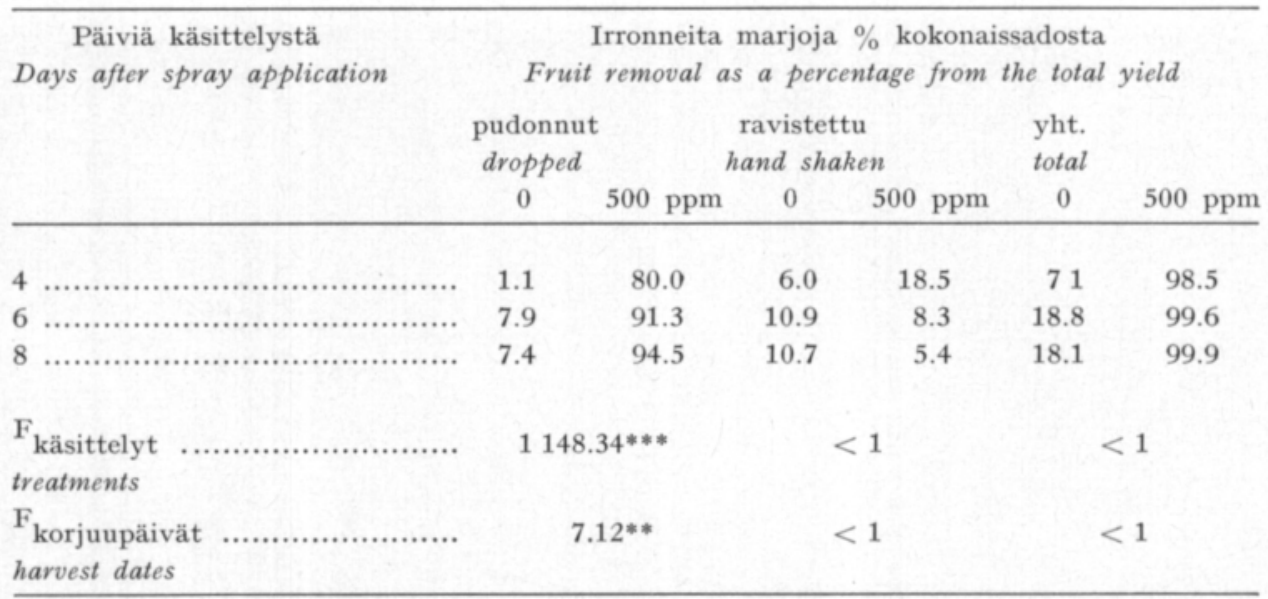

määrään vaikutti lisäksi pensaiden ikä, sillä 'Brödtorp'-lajikkeesta irtosi ennen poimintaa eniten marjoja nuorimmista pensaista (Viikin koe, taulukko 2) ja vähiten vanhimmista pensaista (Tarvasjoki, kuva 2). Lämpöoloissa erot eri koepaikkojen välillä olivat vähäiset (taulukko 1), eikä ethephonin tehossa todetut erot olleet yhdensuuntaisia lämpötilaerojen kanssa. Se, että ennen poimintaa irronneiden marjojen osuus oli selostetuissa kokeissa huomattavan suuri, osoittaa, että marjat tulee poimia aikaisemmin kuin 4 vuorokautta ethephonkäsittelyn jälkeen, etenkin koneellisesti poimittaessa, jolloin käytettävä ravistusvoima on suurempi kuin käsin ravistettaessa. TRUSHEckin ym. (1972) ja INGRAM (1972) ovat päätyneet samanlaiseen suositukseen poimintaajan suhteen. Tosin LuckwILlin (1968) mukaan ethephonin vaikutus marjojen irtoamiseen on todettavissa selvästi vasta 3 vuorokautta käsittelyn jälkeen.

Kokeiden antamien tulosten perusteella $500 \mathrm{ppm}$ tai sitä suurempia vaikuttavan aineen pitoisuuksia käytettäessä varisseiden marjojen määrä tulee liian suureksi. INGRAMin (1972) mukaan jopa 250 ppm:n vaikuttavan aineen määrä voi aiheuttaa liian aikaista marjojen irtoamista kolmen ruiskutusta seuraavan päivän keskilämpötilan ollessa $19.6^{\circ} \mathrm{C}$, mutta ei käsittelyjakson keskilämpötilan ollessa $16.7^{\circ} \mathrm{C}$ (vert. taulukko 1 ).

Vaikutus marjojen kypsmiseen

INGRAM (1973) katsoo ethephonin käytöstä saatavan mustaherukalla selvimmän hyödyn siinä, että se edistää marjojen kypsymistä ja mahdollistaa siten aikaisen poiminnan ja vähentää raakojen marjojen osuutta. Myös muilla marjakasveilla mm. pensasmustikalla (ECK 1970), vadelmalla (JENnings \& CARMichael 1970) ja karviaisella (Costin \& KenNy 1972), on ethephonin havaittu edistävän marjojen kypsymistä. Nyt selostettavissa kokeissa oli neljä vuorokautta käsittelyn jälkeen ethephon lisännyt kypsien marjojen 

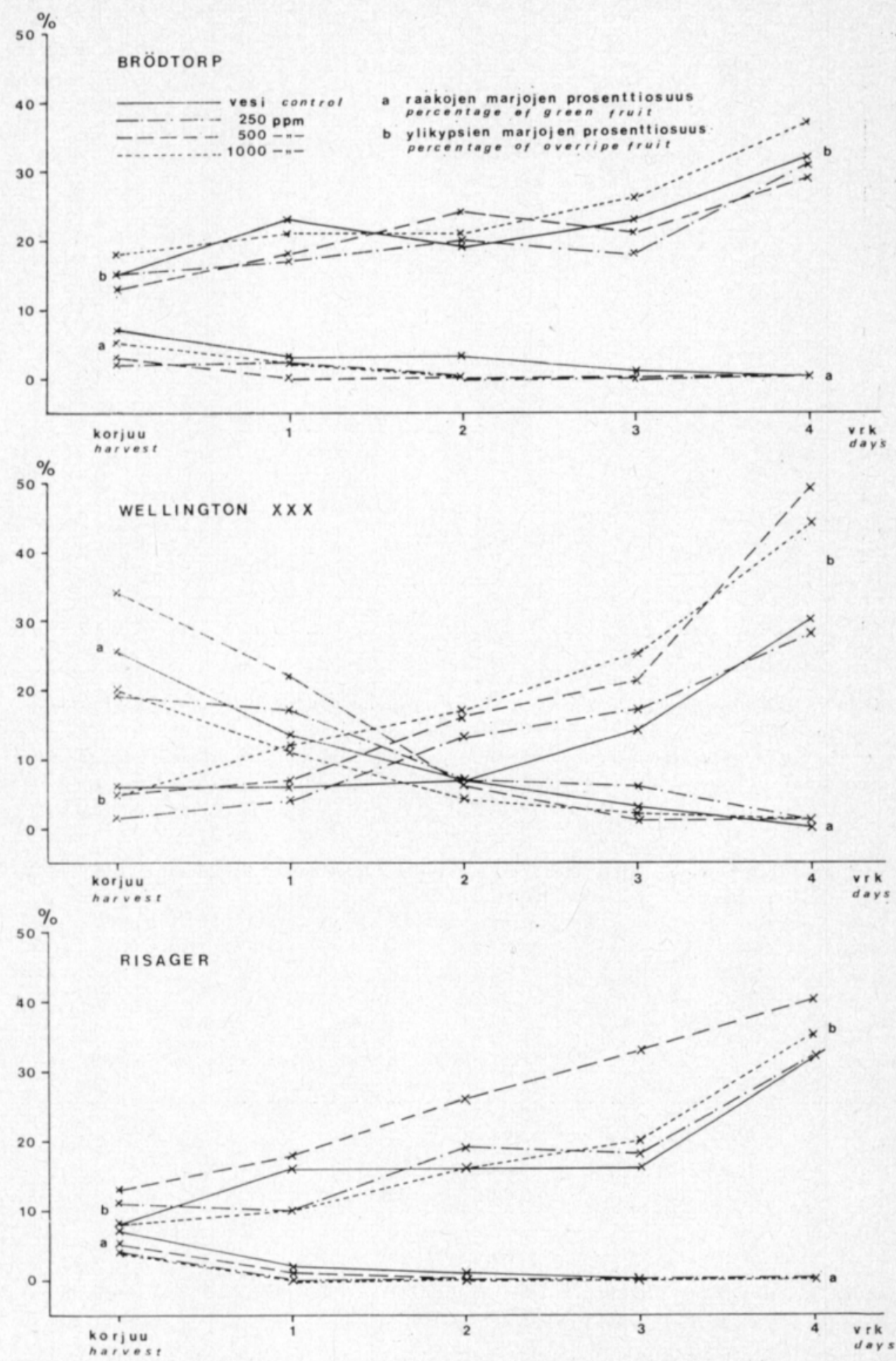

Kuva 2. Ethephon-käsittelyjen vaikutus mustaherukoiden marjojen kypsyysasteeseen korjuupäivänä ja jälkikypsymiseen 4 päivän aikana $20^{\circ} \mathrm{C}: s s a$.

Fig. 2. Effects of the ethephon treatments on the maturity of black currant fruits at harvest and on postharvest ripening in 4 days at $20^{\circ}$. 


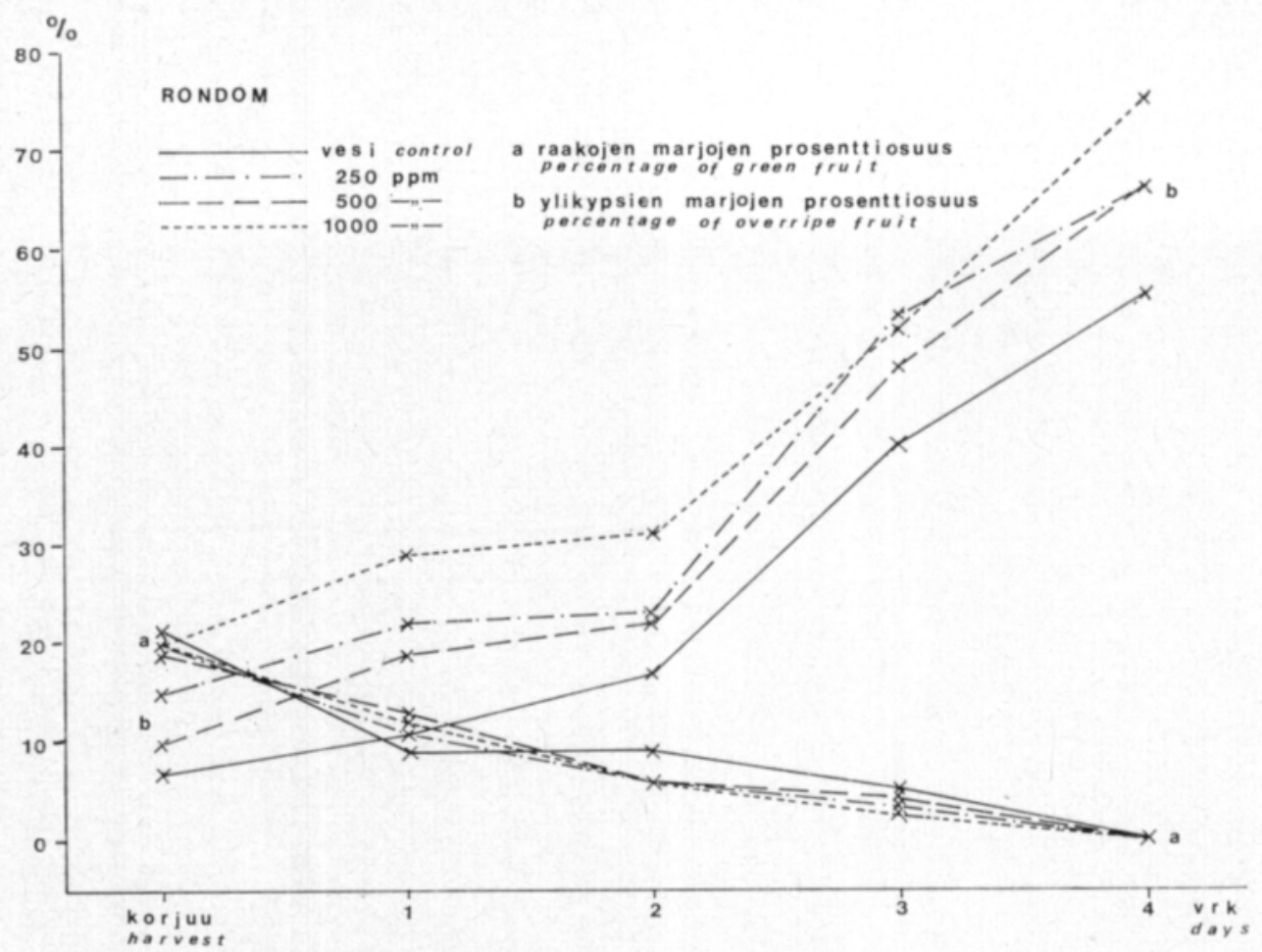

Kuva 3. Ethephon-käsittelyjen vaikutus 'Rondom' punaherukan marjojen kypsyysasteeseen korjuupäivänä ja jälkikypsymiseen 4 päivän aikana $20^{\circ} \mathrm{C}$ :ssa.

Fig. 3. Effects of the ethephon traatments on the maturity of 'Rondom' red currant fruits at harvsot and postharvest ripening in 4 days at $20^{\circ} \mathrm{C}$.

Taulukko 3. Ethephonin (500 ppm) ja korjuupäivän vaikutus 'Brödtorp' mustaherukan marjojen kypsyysasteeseen. Viikki 1970.

Table 3. Effects of ethephon $(500 \mathrm{ppm})$ and date of harvest on maturity of 'Brödtorp' blackcurrants. Viikki 1970.

\begin{tabular}{|c|c|c|c|c|}
\hline \multirow[t]{2}{*}{$\begin{array}{c}\text { Päiviä käsittelystä } \\
\text { Days after spray application }\end{array}$} & \multicolumn{4}{|c|}{$\begin{array}{c}\text { Kypsien marjojen määrä \% } \\
\text { Percentage of mature fruits }\end{array}$} \\
\hline & $\begin{array}{l}\text { ravistetuista }- \\
0\end{array}$ & $\begin{array}{l}\text { shaken } \\
\text { ppm }\end{array}$ & $\begin{array}{c}\text { käsin poimituista } \\
0\end{array}$ & $\begin{array}{c}\text { - hand picked } \\
500 \text { ppm }\end{array}$ \\
\hline $4 \ldots \ldots \ldots$ & 77.3 & 95.7 & 83.4 & 89.8 \\
\hline 6 ….................................... & 94.4 & 00.0 & - & - \\
\hline 8 …................................... & 100.0 & 99.7 & - & - \\
\hline
\end{tabular}

osuutta vain 2-vuotisissa 'Brödtrop'-pensaissa (taulukko 3). Muissa käsittelyissä sen vaikutus kypsymiseen oli epäyhtenäinen (kuva 2). Samoin ethephon ei nopeuttanut raakojen marjojen jälkikypsymistä poiminnan jälkeen (kuvat 2 ja 3). Sen sijaan 'Rondom'-punaherukan kypsissä marjoissa lisääntyi ylikypsien marjojen osuus kaikissa ethephon -käsittelyissä sekä 'Risagen'-mustaherukalla 500 ppm:n käsittelyssä ja 'Wellington'-mustaherukalla 500 ppm:n ja 1000 ppm:n käsittelyissä poiminnan jälkeen nopeammin kuin vesiruiskutuk- 
Taulukko 4. Ethephonin (500 ppm) ja korjuupäivän vaikutus 'Brödtorp' mustaherukan kuivapainoon. Viikki 1970.

Table 4. Effects of ethephon $(500 \mathrm{ppm})$ and date of harvest on dry weight of 'Brödtorp' blackcurrant. Viikki 1970.

\begin{tabular}{|c|c|c|c|}
\hline $\begin{array}{c}\text { Päiviä käsittelystä } \\
\text { Days after spray application }\end{array}$ & $\begin{array}{l}\text { Kuivapa } \\
\text { Dry wei } \\
0\end{array}$ & $\begin{array}{l}\text { no } \mathrm{g} / 100 \mathrm{~g} \\
\text { ht } \mathrm{g} / 100 \mathrm{~g} \\
500 \mathrm{ppm}\end{array}$ & \\
\hline 4 .................................... & 58.23 & 53.32 & $\mathrm{~F}_{\text {käsittelyt }<1}$ \\
\hline 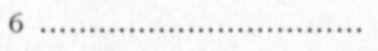 & 55.66 & 62.88 & treatments \\
\hline 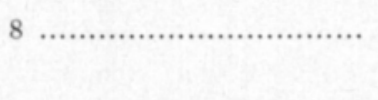 & 52.48 & 57.11 & $\begin{array}{l}\mathrm{F}_{\text {korjuupäivät }}<1 \\
\text { harvest dates }\end{array}$ \\
\hline
\end{tabular}

Taulukko 5. Ethephonin vaikutus kolmen mustaherukkalajikkeen askorbiinihappo- ja sokeripitoisuuteen. Paimio (1) ja Tarvasjoki (2) 1970.

Table 5. Effects of ethephon on ascorbic acid and sugar content of three blackcurrant varieties Paimio (1) and Tarvasjoki (2) 1970.

\begin{tabular}{|c|c|c|c|c|}
\hline \multirow{2}{*}{$\begin{array}{l}\text { Lajike } \\
\text { Variety }\end{array}$} & \multicolumn{3}{|c|}{ Ethephon ppm } & \multirow[b]{2}{*}{1000} \\
\hline & 0 & 250 & 500 & \\
\hline & \multicolumn{3}{|c|}{$\begin{array}{l}\text { Askorbiinihappo } \mathrm{mg} / \mathrm{g} \\
\text { Ascorbic acid } \mathrm{mg} / \mathrm{g}\end{array}$} & \\
\hline Brödtorp (2) ................. & 120.3 & 118.3 & 114.3 & 126.6 \\
\hline Brödtorp (1) ................ & 107.6 & 104.6 & 109.6 & 108.3 \\
\hline 'Wellington $\mathrm{XXX}$ ' .......... & 162.3 & 183.8 & 180.2 & 164.7 \\
\hline Risager ........................ & 103.2 & 100.6 & 119.4 & 116.6 \\
\hline \multirow{2}{*}{$\begin{array}{l}\text { ka ... } \\
\text { mean }\end{array}$} & 124.4 & 129.7 & 136.4 & 129.9 \\
\hline & \multicolumn{3}{|c|}{$\begin{array}{l}\text { Inverttisokeri } \% \\
\text { Invert sugar } \%\end{array}$} & \\
\hline Brödtorp (2) ................. & 4.3 & 4.7 & 5.5 & 5.0 \\
\hline Brödtorp (1) ................. & 7.6 & 6.5 & 4.9 & 4.3 \\
\hline 'Wellington $\mathrm{XXX}$ ' $\ldots . . . . .$. & 5.2 & 6.3 & 6.2 & 6.4 \\
\hline Risager ........................ & 5.0 & 4.7 & 6.0 & 6.4 \\
\hline $\begin{array}{l}\text { ka } \\
\text { mean }\end{array}$ & 5.9 & 5.8 & 5.7 & 5.7 \\
\hline
\end{tabular}

sen saaneessa kontrollissa (kuva 3). Tulosten erilaisuus muualla saatuihin kokemuksiin lienee selitettävissä sen perusteella, että poimintakypsyydelle eri maissa asetettavat vaatimukset ja sen mukaan ethephon-käsittelyn ajankohta eivät ole olleet yhdenmukaisia.

Vaikutus marjojen koostumukseen

Kirjallisuudessa esitettyjen tietojen mukaan ethephon-käsittelyn ansiosta on mm. kirsikan (Andersson 1968), luumun (Proebsting \& Mills 1969) ja persikan (Srms ym. 1974) liukoisen kuiva-aineen pitoisuus lisääntynyt. Nyt 
Taulukko 6. Ethephon käsittelyjen aiheuttama muutos (+ lisäys, - väheneminen) varsiseiden lehtien painossa.

Table 6. Differences (+ increase, - decrease) in weight of dropped leaves induced by ethephon treatments and expressed as percentage from control.

\begin{tabular}{|c|c|c|c|c|c|}
\hline $\begin{array}{l}\text { Aika } \\
\text { käsittelystä } \\
\text { Time after } \\
\text { application }\end{array}$ & $\begin{array}{l}\text { Lajike } \\
\text { Variety }\end{array}$ & $\left.1 \mathrm{x}^{1}\right)$ & $\begin{array}{l}\text { Konsentraa } \\
\text { Concentrat } \\
2 \mathrm{x}\end{array}$ & $4 x$ & $\begin{array}{l}\text { Merkitsevyys } \\
\text { Significance }\end{array}$ \\
\hline $\begin{array}{l}4 \text { päivää } \\
4 \text { days }\end{array}$ & $\begin{array}{l}\text { Brödtorp }{ }^{2} \text { ) } \\
\text { Brödtorp }^{3} \text { ) } \\
\text { Wellington } \mathrm{XXX} \\
\text { Risager } \\
\text { Rondom }\end{array}$ & $\begin{array}{l}-59 \% \\
-12 \% \\
-35 \% \\
+27 \% \\
-4 \%\end{array}$ & $\begin{array}{l}-30 \% \\
+9 \% \\
-23 \% \\
+61 \% \\
-22 \%\end{array}$ & $\begin{array}{l}+97 \% \\
+80 \% \\
-\quad 6.4 \% \\
+169 \% \\
-17 \%\end{array}$ & $\begin{array}{l}\text { a) F-lajikkeet } \\
\text { varietis } \\
10.594^{* * *} \\
\text { b) F-konsentraatiot } \\
\text { concentrations } \\
9.39^{* * *}\end{array}$ \\
\hline $\begin{array}{l}2 \text { viikkoa } \\
2 \text { weeks }\end{array}$ & $\begin{array}{l}\left.\text { Brödtorp }{ }^{2}\right) \\
\text { Brödtorp }^{3} \text { ) } \\
\text { Wellington } \mathrm{XXX} \\
\text { Risager } \\
\text { Rondom }\end{array}$ & $\begin{array}{l}+43 \% \\
+10 \% \\
-29 \% \\
+25 \% \\
-25 \%\end{array}$ & $\begin{array}{l}+24 \% \\
+61 \% \\
-11 \% \\
+58 \% \\
-5 \%\end{array}$ & $\begin{array}{l}+134 \% \\
+126 \% \\
+26 \% \\
+157 \% \\
+15 \%\end{array}$ & $\begin{array}{l}\text { a) } 4.63^{*} \\
\text { b) } 8.60^{* * *}\end{array}$ \\
\hline
\end{tabular}

1) $1 \mathrm{x}=250 \mathrm{ppm}$ ethephonia muille paitsi Rondom-lajikkeelle $500 \mathrm{ppm}$.

$1 x=250 \mathrm{ppm}$ of ethephon exept on variety Rondom $500 \mathrm{ppm}$.

$\left.{ }^{2}\right)$ Tarvasjoen kokeesta

From experiment at Tarvasjoki

3) Paimion kokeesta

From experiment at Paimio

selostettavista kokeista tehtyjen määritysten mukaan ethephonin vaikutus marjojen kuıvapainoon (taulukko 4), inverttisokeri- ja askorbiinihappopitoisuuteen (taulukko 5) oli epäyhtenäinen. Mainituissa suhteissa ethephonin vaikutus oli riippuvainen lähinnä marjojen kypsyysasteesta. Tähän viittaa se, että vain 'Wellington'-lajikkeella, jolla raakojen marjojen osuus poimittaessa oli suurempi kuin muilla lisääntyi askorbiinihappo- ja inverttisokeripitoisuus kaikissa ethephon-käsittelyissä.

Vaikutus lehtien irtoamiseen

Hedelmien ja marjojen irroittamiseksi tehdyn ethephon-käsittelyn on todettu eräissä tapauksissa aiheuttavan niin runsaan lehtien abskission, että sen seurauksena seuraavan vuoden sato pienenee (BUKovac \& ZUCConi 1970, Fiorino ym. 1970). Nyt selostettavissa kokeissa mitattiin varisseiden lehtien paino marjojen poiminnan yhteydessä sekä määrävälein poiminnan jälkeen. Taulukossa 6 esitetään ethephonin vaikutus irronneiden lehtien määrään poimintahetkellä sekä 2 viikkoa käsittelyn jälkeen. Ethephonin vaikutus lehtien irtoamiseen oli erilainen eri lajikkeilla ja oli konsentraatiosta riippuvainen. Pienin käytetyistä ruiskuteväkevyyksistä lisäsi lehtien irtoamista poimintaravistelun yhteydessä vain 'Risager'-lajikkeesta ja 2 viikkoa käsittelyn jälkeen 'Risager'- ja 'Brödtorp'-lajikkeista. Muilla lajikkeilla pienin käyttöväkevyys vähensi lehtien varisemista vesiruiskutukseen verrattuna. 
Suurin käyttöväkevyys puolestaan lisäsi varisseiden lehtien määrää kaikilla lajikkeilla 2 viikkoa käsittelyn jälkeen mitattuna, mutta korjuun yhteydessä vain 'Risager'- ja 'Brödtorp'-lajikkeilla. On siis ilmeistä, että ethephon vaikuttaa nopeammin marjojen kuin lehtien irtomiseen.

Kun pienin käsittelyväkevyys oli riittävä edistämään marjojen irtoamista on ilmeistä, että mustaherukalla ethephonin aiheuttama lehtien variseminen jää käytännön kannalta merkityksettömäksi nuorissa satoikäisissä kasvustoissa (vert. Brödtorp (2) ja Brödtorp (3) taulukko 6).

\section{Yhteenveto}

Ethephonin (2-kloorietyylifosforihapon) abskissiovaikutusta eräissä Suomessa viljeltävissä herukkalajikkeissa tutkittiin kolmessa kokeessa, joissa kaikissa koelajikkeena oli 'Brödtorp'-mustaherukka sekä lisäksi Paimiossa mustaherukat 'Wellington XXX' ja 'Risager' ja punaherukka 'Rondom'. Ethephon ruiskutettiin 4 päivää ennen sadon korjuutta.

Ethephon lisäsi irronneiden marjojen määrää kaikissa koelajikkeissa ja kaikilla koepaikoilla. Ethephonin teho suureni ruiskutteen pitoisuuden kasvaessa. Ennen koesuunnitelman mukaista korjuupäivää (4 vrk käsittelyn jälkeen) pudonneiden marjojen osuus koko sadosta oli lajikkeesta ja koeoloista riippuen $0.6-13.1 \% 250$ ppm:n, 16. 7-78.9 \% 500 ppm:n ja $34.1-84.0 \%$ 1000 ppm:n ruiskuteväkevyyttä käytettäessä. Ennen poimintaa varisseiden marjojen määrä oli pienin 'Wellington XXX' mustaherukalla ja 'Rondom'punaherukalla.

Poimitun sadon raakojen marjojen suhteellinen osuus pieneni ethephonkäsittelyn johdosta vain nuorissa 'Brödtorp'-pensaissa. Ethephon ei nopeuttanut raakojen marjojen jälkikypsymistä, mutta sen sijaan ylikypsien marjojen osuus kypsissä marjoissa lisääntyi 'Rondom'-punaherukalla kaikissa ethephonkäsittelyissä, 500 ja 1000 ppm:n käsittelyissä 'Wellington XXX'- ja 500 ppm:n käsittelyssä 'Risager'-mustaherukalla.

Ethephonin vaikutus marjojen sokeri- ja askorbiinihappopitoisuuteen oli epäyhtenäinen.

Ethephon-käsittelyt lisäsivät lehtien irtoamista herkemmin 'Risager'- ja 'Brödtorp'-lajikkeilla kuin 'Wellington'- ja 'Rondom'-lajikkeilla. 'Risager'lajikkeella lehtien variseminen ilmeni jo 4 vrk käsittelyn jälkeen kaikissa ethephon-käsittelyissä, kun taas 'Brödtorp'-lajikkeella pienin käyttömäärä (250 ppm) lisäsi lehtien varisemista vasta 2 viikkoa käsittelyn jälkeen.

\section{KIRJALLISUUS}

ACKer, L. 1967. Kohlenhydrate, Nachweis und Bestimmung der Mono-Oligosaccharide. Handbuch der Lebensmittelchemie II/2: 338-436.

Andersson, J. L. 1969. The effect of Ethrel on the ripening of Montmorency sour cherries. Hort. Sci. 4: 92-93.

Bukovac, M. J. \& Zucconi, F. 1970. Promotion of cherry fruit abscission in relation to mechanical harvest. Proc. 18th Int. Hort. Congr. 1: 54.

Cantliffe, D. J. \& Goodwin, P. 1975. Red color enhancement of pepper fruits by multiple applications of ethephon. J. Amer. Soc. Hort. Sci. 100: 157-161. 
Costrn, J. J. \& Kenny, T. A. 1972. Effects of 2-chloroethylphosphonic acid (Ethrel) on gooseberries. Pesticide Sci. 3: 545-550.

Eck, P. 1970. Influence of Ethrel upon highbush blueberry fruit ripening. Hort. Sci. 5: $23-25$.

Fiorino, P., Vitagliano, C. \& Zucconi, F. 1970. Inducing olive fruit abscission by chemical treatments. Pros. 18th Int. Hort. Congr. 1: 119.

Ingram, J. 1969. Mechanical harvesting of the blackcurrant crop. Comm. Grower 3842: 144145.

- - 1972. Black currant: Mechanical harvesting - use of ethephon to induce fruit abscission 1972 LD 88 (Progress report). 23rd Ann. rep. Luddington Exp. Hort. Sta 1: $69-71$.

Jennings, D. L. \& Carmichael, E. 1970. Ethrel, not a ready answer to rasberry harvesting problems. Grower 73: 86-87.

Kontio, P. \& CASAgrande, 1945. Askorbiinihapon potentiometrinen määräämistapa. Suomen Kemistilehti 18: 208-211.

Lougheed, E. C. \& Frankin, E. W. 1972. Effects of temperature on ethylene evolution from ethephon. Can. J. Plant. Sci. 52: 769-773.

LUckwill, C. L. 1968. Is this good-bye to traditional harvesting? Grower 70:475-477.

Proesting, E. L., Jr. \& Mills, H. H. 1969. Effects of 2-chloroethanephonic acid and its interaction with gibberellic acid on quality of 'Early Italian' prunes. J. Amer. Soc. Hort. Sci. 94: 443-446.

Sims, E. T., Jr., Cambrell, C. E. Jr. \& Stembridge, G. E. 1974. The influence of (2 chloreothyl) phosphonic acid on peach quality and maturation. J. Amer. Soc. Hort. Sci. 99: 152155.

Trusheckin, V. G., Pankova, T. F., Ostreiko, S. A. \& Kortov, A. M. 1972. Ethrel and mechanized soft fruit harvesting. Sadovodstvo 1972, 8:24-25.

Westwood, M. N. 1968. Some factors affecting abscission of stone fruits. Proc. Oregon Hort. Soc $60: 51-59$.

de WILDE, R. C. 1970. Practical applications of Ethrel in agricultural production. Symposium of ethylene. 67th Ann. Meet. Amer. Soc. Hort. Sci. p. 21.

Käsikirjoitus saapunut 1.12.1975 